\title{
New Zealand Land Search and Rescue Operations: An Analysis of Medical and Traumatic Conditions
}

\author{
Jenny T. Visser, MbChB, MTravMed; Adam F.R. Campbell \\ From the Department of Primary Health Care and General Practice, University of Otago, Wellington, New Zealand (Dr Visser); Medical Student, \\ University of Otago, Wellington, New Zealand (Mr Campbell).
}

Objective.-The aim of this study was to describe the range and types of medical and traumatic conditions encountered in land search and rescue operations in New Zealand.

Methods.-Twenty months (May 2010 to December 2011) of land search and rescue operations were analyzed. Data on medical and traumatic conditions were extracted from the New Zealand Police search and rescue database.

Results.-During the period audited, New Zealand Police coordinated 1490 land-based search and rescue operations, from which 611 persons fulfilled the study inclusion criteria. Males accounted for $60.5 \%$ of the subjects, and a trauma-related injury was the most commonly encountered condition (37.3\% of all). The lower limb was the most commonly injured body site, and most injuries occurred as the result of a slip or fall. Medical conditions were recorded in $11.6 \%$ of operations and included a wide spread of conditions, with cardiovascular events being seen most frequently. Hypothermia was diagnosed in $9.3 \%$ of all operations, and fatalities made up $5.6 \%$ of the sample. Thirty percent of all operations were for persons with cognitive impairment who had wandered away from their usual place of residence. These were almost entirely urban searches and concentrated in districts with large populations.

Conclusions.- Search and rescue personnel are exposed to a broad range of medical and traumatic conditions. In New Zealand, they include preexisting cognitive impairment that results in persons lost in urban environments. Notwithstanding this, many subjects will also need to be managed in remote, resource-limited environments for extended periods. First aid training and field equipment should reflect these demands.

Key words: search, rescue, injury, illness, New Zealand

\section{Introduction}

Significant numbers of people venture into New Zealand's wilderness areas to participate in recreational activities each year. When compared to residents of other countries, New Zealand residents score highly in overall levels of physical activity. ${ }^{1}$ Many sporting and recreational activities are undertaken in outdoor and wilderness areas. $^{2}$ The dramatic increase in absolute numbers of New Zealand residents participating in outdoor and wilderness activities seen in the 1970s and $1980 \mathrm{~s}^{3}$ may now be stabilizing. ${ }^{4}$ Still, in 2009, many New Zealanders reported participation in a range of outdoor activities, including walking, 64\%; hiking,

Corresponding author: Jenny $\mathrm{T}$ Visser, DPH\&GP, University of Otago, PO Box 7343, Wellington South 6242, New Zealand (e-mail: jenny.visser@otago.ac.nz).
9.4\%; mountain biking, 6\%, and mountaineering, $1.1 \%{ }^{2}$ New Zealand is also a destination for outdoor recreational activities for many international visitors. Some outdoor enthusiasts will become lost, ill, or injured and may require the services of search and rescue (SAR) organizations.

In New Zealand, SAR operations are divided into category 1 operations (land, inland waterway, subterranean, and marine close to shore) and category 2 operations (aircraft, marine offshore, and activated emergency locator beacons). Category 1 operations are coordinated by New Zealand Police (NZ Police), and category 2 operations, by the NZ Rescue Coordination Center. ${ }^{5}$ Category 1 operations can occur in wilderness and suburban/urban locations. Suburban/urban operations are largely searches for missing persons. That differs from the responsibilities of the NZ urban SAR 
(USAR), who, under the umbrella of the NZ Fire Service, are responsible for the rescue and extraction of persons trapped in collapsed structures. ${ }^{6}$ The SAR responsibilities within NZ Police are devolved to police districts where police are assisted by New Zealand land search and rescue (LandSAR) volunteers.

In the year from 2011 to 2012, NZ Police coordinated 1675 category 1 SAR operations, of which 920 were land based. ${ }^{5}$ New Zealand LandSAR volunteers were involved in 421 of these operations, contributing almost 30,000 volunteer operation hours. ${ }^{7}$ One of the roles of SAR personnel (both NZ Police and NZ LandSAR volunteers) is to provide first aid to the victim. Although statistics are gathered on SAR operation logistics, there has been no formal audit of the types of medical and traumatic conditions encountered by SAR personnel in New Zealand. The cost of training and equipping of SAR personnel is borne by NZ LandSAR, NZ Police, and by the volunteers themselves. Information on medical and traumatic conditions that personnel are likely to encounter will help rationalize both training and field equipment (including contents of medical kits). That should maximize the use of limited funds and ensure best victim care.

Studies of medical and traumatic conditions encountered in search and rescue operations in a number of countries have been published. ${ }^{8-21}$ Only one, a review of mountaineering fatalities, has been found for New Zealand. ${ }^{22}$ Although both the outdoor environment of New Zealand and the activities undertaken in the outdoors have a number of similarities to those of Europe and North America, differences, including its noncontinental (and therefore less predictable) climate and variable terrain found over relatively short geographical distances, may result in a different mix of medical and traumatic conditions, requiring verification by NZspecific data.

The objective of this audit was to describe the range and types of medical and traumatic conditions encountered in land search and rescue operations in New Zealand.

\section{Methods}

Twenty months (May 2010 to December 2011) of category 1 land SAR operations were analyzed. Data on medical and traumatic conditions were extracted from the NZ Police SAR database. Conditions were grouped into 6 broad categories: traumatic injuries; cognitive impairment (dementia, autism, and intellectual disability); medical conditions (exhaustion, dehydration, and all acute illness-either de novo or due to a preexisting medical condition); hypothermia; and "despondent" (suicidal or other acute psychiatric condition). Use of alcohol and drugs was also noted. All fatalities were recorded. Operations that were purely retrievals of well persons were excluded from the analysis.

Ethics approval was provided by the University of Otago and by the NZ Police Research and Evaluation Steering Committee.

\section{Results}

During the period audited, NZ Police coordinated 1490 category 1 land SAR operations. ${ }^{5,23}$ Of these, at least 1 medical or traumatic condition was recorded in 611 (41\%), fulfilling the audit inclusion criteria. The operations audited were spread across urban/suburban and wilderness locations throughout all NZ Police districts. Wilderness locations accounted for $60.5 \%$ of operations. Bay of Plenty, Southern, and Canterbury police districts together accounted for approximately half the operations. There was an almost even split in operations occurring in the North Island and the South Island (Table 1).

Ages of the SAR subjects had a wide range, from 3 to 94 years, with a mean age of 47.9 years. The mean age dropped to 40.1 years when operations for persons with cognitive impairment were excluded (Table 2). Male subjects accounted for $60.5 \%$ of the sample (Table 2).

For the 611 subjects, 657 medical and traumatic conditions were recorded (Table 2). Trauma accounted for $37.3 \%$, cognitive impairment for $27.9 \%$, and nontraumatic medical conditions for $11.6 \%$. Hypothermia was recorded in $9.3 \%$ of cases. The 76 medical conditions (Table 3) were led by cardiovascular and nonspecific "collapse" (some of which may have been precipitated by cardiovascular events). Some were known preexisting conditions that did not necessarily contribute to the need for the SAR operation; they were noted coincidentally (Table 3). For example, a history of asthma was noted in 4 persons; however, for all 4 , it had not contributed to the need for the SAR operation. In contrast, all cases of a cardiovascular event did contribute to the need for the subsequent SAR operation.

In the analysis it became apparent that there was a clear split between 2 types of operations, those for a group subsequently labeled "wanderers" and a second group labeled "nonwanderers" (Table 2). Wanderers were defined as persons with preexisting cognitive impairment who had gone missing from their home or residential care. These searches were largely in urban/ suburban areas and were concentrated in the more populous North Island; they accounted for $30 \%$ of the sample. The proportion that such operations contributed to the overall workload in any given district varied greatly. In the Auckland City District, for example, 
Table 1. Operations by police district

\begin{tabular}{|c|c|c|c|c|}
\hline Police district & Wanderers, $n(\%)$ & Nonwanderers, $n(\%)$ & Wanderer operations, \% & Total, $n(\%)$ \\
\hline North Island & $139(76)$ & $188(44)$ & 42.5 & $327(53.5)$ \\
\hline Northland & $9(4.9)$ & $6(1.4)$ & 51.1 & $15(2.5)$ \\
\hline Auckland City & $48(26.2)$ & $21(4.9)$ & 69.1 & $69(11.3)$ \\
\hline Counties-Manukau & $9(4.9)$ & $7(1.6)$ & 56.3 & $16(2.6)$ \\
\hline Waikato & $15(8.2)$ & $28(6.5)$ & 34.9 & $43(7.0)$ \\
\hline Bay of Plenty ${ }^{a}$ & $40(31.9)$ & $69(16.1)$ & 36.7 & $109(17.8)$ \\
\hline Central & $3(1.6)$ & $26(6.1)$ & 10.3 & $29(4.7)$ \\
\hline Eastern & $2(1.1)$ & $9(2.1)$ & 18.2 & $11(1.8)$ \\
\hline Wellington & $13(7.1)$ & $22(5.1)$ & 37.1 & $35(5.7)$ \\
\hline South Island & $44(24)$ & $240(56)$ & 15.5 & $284(46.5)$ \\
\hline Tasman & $10(5.5)$ & $73(17.1)$ & 12 & $83(13.6)$ \\
\hline Canterbury & $30(16.4)$ & $64(15)$ & 31.9 & $94(15.4)$ \\
\hline Southern $^{b}$ & $4(2.2)$ & $103(24.1)$ & 3.7 & $107(17.5)$ \\
\hline All New Zealand & 183 & 428 & 30 & 611 \\
\hline
\end{tabular}

\footnotetext{
${ }^{a}$ Including Ruapehu (16) and Tongariro (19).
}

${ }^{b}$ Including Wanaka (42), Otago/Southland (32), and Fiordland (33).

$69.1 \%$ of all audited operations involved wanderers. In contrast, wanderers made up only $3.7 \%$ of operations in the Southern District. The wanderers group had a bimodal age distribution consisting of children with either autism or intellectual disability at one extreme and elderly persons with dementia at the other (Figure 2). The remaining $70 \%$ of operations were for nonwanderers; in contrast to wanderer operations, they were predominantly wilderness searches $(82.3 \%)$. The majority of nonwanderer search subjects had traumatic injuries $(52.8 \%)$ or acute medical conditions (16.2\%) (Table 1).

For 319 of 611 subjects, information was recorded on the activity being undertaken. Hiking was the most commonly recorded activity $(56.7 \%)$; hunting at $7.5 \%$ and mountain biking at $6.2 \%$ were distant second and third most common activities (Figure 1). In many cases it was not applicable to record an activity, as in the case of persons with cognitive impairment who wandered away from their homes or place of residence.

Table 2. Demographics, conditions and operation location

\begin{tabular}{lccc}
\hline \multicolumn{1}{c}{ Demographics } & Wanderers, $n(\%)$ & Nonwanderers, $n(\%)$ & \\
\hline Gender & & & \\
Male & $109(59.6)$ & $261(61)$ & $370(60.5)$ \\
$\quad$ Female & $74(40.4)$ & $167(39)$ & $241(39.5)$ \\
$\quad$ Total & $183(30)$ & $428(70)$ & $611(100)$ \\
Age, years, mean & 66.4 & 40.1 & 47.9 \\
$\quad$ Range & $5-94$ & $3-86$ & $3-94$ \\
ConditionsTraumatic injuries & 1 & $244(52.8)$ & $245(37.3)$ \\
Cognitive impairment & 183 & $0(0)$ & $183(27.9)$ \\
Medical/nontrauma & 1 & $75(16.2)$ & $76(11.6)$ \\
Hypothermia & 6 & $55(11.8)$ & $61(9.3)$ \\
Fatalities & 2 & $35(7.5)$ & $37(5.6)$ \\
Despondent & 0 & $38(8.2)$ & $38(5.8)$ \\
Alcohol/drug & 1 & $16(3.4)$ & $17(2.6)$ \\
Total & 194 & 464 & 657 \\
Operation location & & $10(2.6)$ & $171(28.1)$ \\
Urban/suburban & $161(88)$ & $353(82.3)$ & $370(60.5)$ \\
$\quad$ Wilderness & $17(9.2)$ & $65(15.2)$ & $70(11.4)$ \\
Not recorded & $5(2.7)$ & 428 & 611 \\
Total & 183 & & \\
\hline
\end{tabular}


Table 3. Medical conditions, excluding cognitive impairment

\begin{tabular}{|c|c|c|c|c|}
\hline Condition & $n$ & $\%$ & $\begin{array}{c}\text { Number contributing } \\
\text { to need for } S A R \\
\text { operation }\end{array}$ & $\begin{array}{c}\text { Percent contributing } \\
\text { to need for } S A R \\
\text { operation }\end{array}$ \\
\hline Cardiovascular & 19 & 25 & $19 / 19$ & 100 \\
\hline Collapse & 9 & 11.8 & $9 / 9$ & 100 \\
\hline Mental illness & 8 & 10.5 & $1 / 8$ & 12.5 \\
\hline Exhaustion/dehydration & 11 & 14.5 & $11 / 11$ & 100 \\
\hline Allergy/anaphylaxis & 5 & 6.6 & $5 / 5$ & 100 \\
\hline Vomiting, diarrhea/abdominal & 7 & 9.2 & $7 / 7$ & 100 \\
\hline Asthma & 4 & 5.3 & $0 / 4$ & 0 \\
\hline Diabetes mellitus & 4 & 5.3 & $1 / 4$ & 25 \\
\hline Other & 9 & 11.8 & $4 / 9$ & 44.4 \\
\hline Total & 76 & 100 & & \\
\hline
\end{tabular}

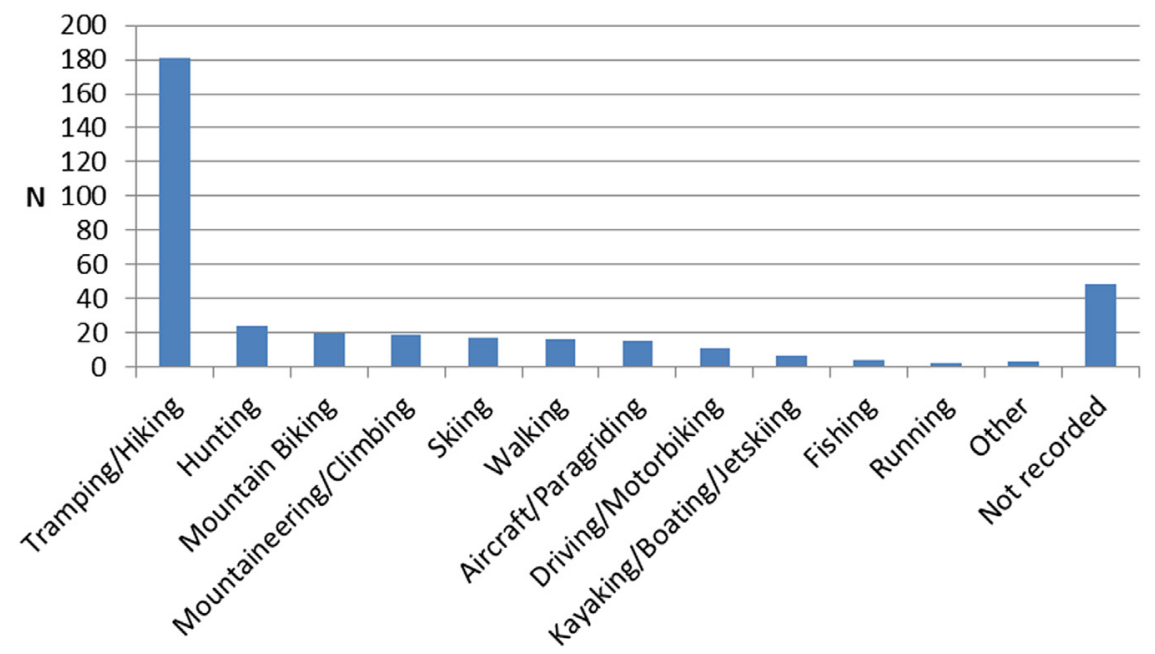

Figure 1. Activity of persons who are subjects of search and rescue operations.

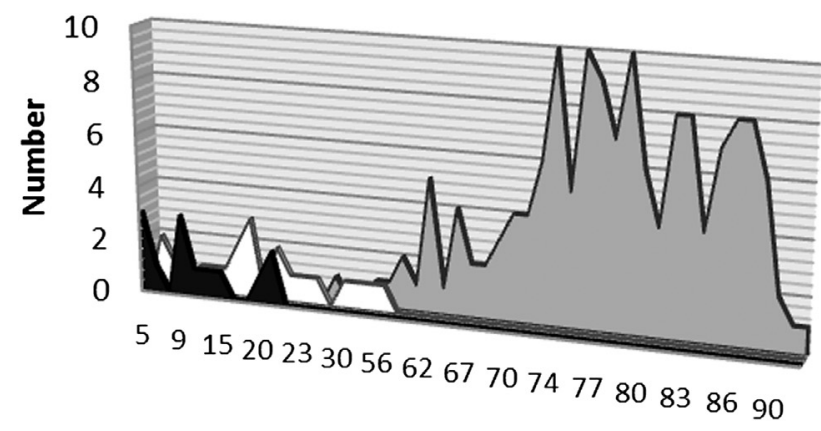

Autism

$\square$ Mental Disability

$\square$ Dementia

\section{Age}

Figure 2. Age distribution of different types of wanderers. Black area, autism; white area, mental disability; gray area, dementia. 
Table 4. Known preexisting conditions

\begin{tabular}{lrr}
\hline \multicolumn{1}{c}{ Condition } & $n$ & $\%$ \\
\hline Cognitive impairment & 183 & 92 \\
Mental illness & 8 & 4 \\
Diabetes mellitus & 4 & 2 \\
Asthma & 4 & 2 \\
Total & 199 & 100 \\
\hline
\end{tabular}

There were 199 recorded known preexisting medical conditions in 194 subjects (Table 4). For 183, that was cognitive impairment. Other preexisting conditions included mental illness ( 8 persons), asthma (4 persons), and diabetes (4 persons). Only for persons with cognitive impairment and for 1 person with diabetes mellitus was the preexisting medical condition recorded as a factor in the need for the SAR operation.

The 245 incidents of trauma resulted in 274 separate injuries (Table 5), with the most common mechanism of injury being a fall or slip (Table 6). Fifty-three percent of the injuries were sprains or strains, and $28.9 \%$ were fractures (Table 5). The lower limb was the most common site of injury (52.2\%). Thirty-seven fatalities were recorded (Table 2), of which $67.6 \%$ were by suicide. The remaining fatalities were due to either trauma $(18.9 \%)$ or drowning $(13.5 \%)$.

\section{Discussion}

That males are over-represented in SAR statistics is a finding common to many studies ${ }^{11-14,16,18-20}$ and likely represents sex differences in outdoor activities. Although males accounted for nearly two thirds of the sample in this audit, there was no evidence that males and females differed in major categories of medical or traumatic conditions. The mean age recorded in this audit was slightly higher than that reported in overseas studies. $^{11,15,17,21}$

Table 5. Trauma cases injury type

\begin{tabular}{lcc}
\hline \multicolumn{1}{c}{ Injury type } & $n$ & $n(\%)$ \\
\hline Sprains/strains & & $145(53)$ \\
Fractures & & $79(28.9)$ \\
$\quad$ Lower limb & 45 & \\
$\quad$ Upper limb & 16 & \\
$\quad$ Neck/back & 7 & \\
$\quad$ Other fracture & 11 & $28(10.2)$ \\
Contusions/lacerations & & $20(7.3)$ \\
Head injuries & & $2(0.7)$ \\
Burns & & $274(100)$ \\
Total & & \\
\hline
\end{tabular}

Table 6. Mechanism and site of injury in trauma cases

\begin{tabular}{lr}
\hline Mechanism and site & $n(\%)$ \\
\hline Mechanism of injury & \\
Fall/slip & $171(69.8)$ \\
Not recorded & $38(15.5)$ \\
Air/car/motorbike crash & $21(8.6)$ \\
Mountain bike crash & $3(1.2)$ \\
Other & $12(4.9)$ \\
Total & $245(100)$ \\
Body site & \\
Lower limb & $128(52.2)$ \\
Upper limb & $27(11.0)$ \\
Head/neck & $27(11.0)$ \\
Not recorded & $21(8.6)$ \\
Other & \\
Total & $42(17.1)$ \\
& $245(100)$ \\
\hline
\end{tabular}

${ }^{a}$ Chest/abdomen/back, 36 of 42.

Medical conditions were recorded for $11.6 \%$ of subjects, a percentage similar to that seen in studies from the United States. ${ }^{12,16,17}$ In keeping with findings from this audit, cardiovascular events have been noted as the leading medical condition and the leading cause of nontrauma-related fatalities in a number of US SAR analyses. ${ }^{11,12,15,17,18,21,24}$ Medical conditions also included persons who had dehydration and exhaustion, causes that have been noted in other studies. ${ }^{12,14,15}$

Not surprisingly, given the temperate maritime, rapidly changeable nature of the New Zealand climate, hypothermia was commonly encountered and was noted for $9.3 \%$ of all subjects. Unfortunately, it was not clear from this dataset whether hypothermia was a primary or secondary reason for the operation. Hypothermia in a significant proportion of SAR subjects has been reported in studies from colder environments, including Alaska, ${ }^{12,13,16}$ Yosemite, ${ }^{15}$ and Banff National Parks, ${ }^{11}$ and among long-distance hikers in Vermont. ${ }^{25}$

That trauma-related injuries made up a significant proportion of all conditions was in keeping with overseas studies of both SAR operations and wilderness injuries, ${ }^{15-17,24-26}$ as were the findings that slips and falls accounted for most $(69.8 \%)$ of the injuries and that the lower limb was the site most often affected. ${ }^{10-14,17,18,24}$

Dealing with fatalities is common for SAR teams the world over. ${ }^{15,18,20}$ Compared with other studies, ${ }^{20,21,27}$ the relative proportion noted as a result of suicide $(67.6 \%)$ was higher in the New Zealand data. The reason for that is not entirely clear, but in New Zealand, many trauma-related fatalities are likely to be relatively straightforward body retrievals (which usually do not require the activation of SAR), whereas deaths by suicide almost always require intensive searching. 
In a review of wilderness mortalities in Arizona, ${ }^{27}$ many deaths were noted to be related to incidents involving alcohol. In this audit, a suicide but none of the traumarelated fatalities involved the use of alcohol or drugs. However, use of alcohol or drugs was noted for $29 \%$ of the despondents.

When activities were recorded, $57 \%$ of subjects had been hiking before requiring rescue, similar to percentages described in overseas studies. ${ }^{10,11,14,15,17-21,24}$ Not surprisingly, the relative mix of activities varied between districts, reflecting popular local activities. For example, skiing contributed the bulk of operations in Ruapehu, an area incorporating 2 major ski fields. Hiking made up a larger proportion of recorded activity in Waikato, Bay of Plenty, Tasman, Canterbury, and Southland, all areas incorporating popular hiking destinations. Similarly, most mountaineering/climbing incidents occurred in Bay of Plenty and Southland, areas containing popular mountaineering peaks. Similar clustering of activities has been described in other studies. ${ }^{20}$

The observations that in New Zealand there was a clear split between searches for wanderers (those with preexisting cognitive impairment) and nonwanderers and that searches for wanderers made up such a large proportion of searches have not been described elsewhere. Given the relatively small population of New Zealand, SAR districts often cover large geographical areas. As a result, NZ Police and NZ LandSAR members are likely to be involved in operations in both suburban/ urban and wilderness areas, with the proportional mix of operation location largely reflecting local population density. Although an international study made mention of missing persons, ${ }^{15}$ no study made specific mention of cognitive impairment as a precipitating medical reason for a SAR operation. It is possible that in other countries, these predominantly urban SAR operations are not the responsibility of persons also responsible for wilderness SAR operations. Also, in some published studies, such operations were deliberately excluded from analysis. ${ }^{17}$

The NZ LandSAR and NZ Police personnel involved in field operations should hold, as an absolute minimum, a basic first aid certificate. In addition, nominated first aiders are required to demonstrate outdoor first aid skills. $^{28}$ Some SAR groups, for example Alpine Cliff Rescue, have sponsored personnel to undertake more extensive prehospital emergency care training. The findings of this audit indicate that SAR personnel need to be trained and equipped to deal with a wide range of medical and traumatic conditions. They also need to be prepared to manage all ages of subjects, from children to the elderly. In New Zealand, that includes dealing with persons with cognitive impairment, especially for members of SAR teams based in and near urban centers.
This finding would also support the widened use of personal electronic tracking devices ${ }^{29}$ or other preventive strategies for persons with dementia, known to be at risk for wandering. Training in and use of models based on probable lost person behavior helps refine search area and search technique ${ }^{30}$ and should include models for subjects with cognitive impairment, particularly dementia (the largest group of wanderers in this audit).

The SAR personnel may also encounter suicidal persons $(5.8 \%$ of the sample was described as despondents, and 25 of 37 fatalities were suicides). The acute management of a suicidal person by essentially lay persons in a remote setting is not without its challenges. Again, training needs to reflect that and needs to include advice on approaching and caring for the acutely suicidal person while maintaining personal safety.

These reflections aside, the finding that trauma-related musculoskeletal and soft-tissue injuries form the bulk of diagnoses in wilderness SAR operations reinforces that it is entirely appropriate that skills to deal with these conditions form the core of NZ LandSAR first aid training. ${ }^{28}$ Current NZ LandSAR guidelines on contents of medical kits for use by SAR teams in the field ${ }^{31}$ (Table 7) appropriately places the emphasis on first aid items to deal with traumarelated injuries. They also recommend that kits contain a number of medications that can be administered in the field by SAR personnel under remote guidance (radio or telephone communications) with an appropriate health professional. ${ }^{31}$ The NZ LandSAR groups are encouraged to identify a local health professional who is willing to be involved in training and available to provide advice during operations. The NZ LandSAR guidelines state that medications should be included in kits only when groups have identified such a health professional. Anecdotally, this is working well in a number of districts. Pain relief would appear fully justified by the number of traumatic conditions encountered. The inclusion of first aid cardiac medication (aspirin, glyceryl trinitrate spray) appears justified by the number of cases with previously unknown cardiovascular conditions. Five cases were attributed to allergy, 2 of which were anaphylaxis. Although anaphylaxis is a rare event, the urgency of its treatment would support kits containing antihistamine and adrenalin. And although an exacerbation of asthma was not recorded as contributing to a SAR operation in this audit, 4 persons had a history of asthma and backup medication in kits would seem sensible.

\section{Limitations}

A limitation of this audit is that it provides only a snapshot of SAR operations. Findings might be different if a longer time and a larger sample were audited. The small sample size also limited more specific 
Table 7. New Zealand suggested contents of field team and patient first aid kits ${ }^{\mathrm{a}}$

\begin{tabular}{l} 
Item \\
\hline Notepad, pencil, NZ LandSAR casualty assessment forms \\
Contents list (with quick guide to use of contents) \\
Aides memoire: field first aid, CPR \\
CPR face shield \\
Plastic bags, safety pins \\
Disposable gloves \\
Alcohol-based hand sanitizer \\
Triangular bandage \\
Crepe bandages (various sizes) \\
Wound dressings, combine dressings, tape, adhesive wound \\
closure strips \\
Gauze squares, eye pads, nonadherent dressings \\
Adhesive plasters (various sizes), occlusive dressings \\
Iodine solution \\
Oropharyngeal airway \\
Low reading thermometer \\
Survival blanket \\
Normal saline 30 mL \\
Scissors, tweezers \\
Syringe and hypodermic needle \\
Scalpel blades \\
Alcohol skin wipes \\
Promethazine 10 mg tablets \\
Acetaminophen 500 mg tablets \\
Diclofenac 50 mg tablets, 100 mg suppositories \\
Tramadol 150 mg capsules \\
Glyceryl trinitrate pump spray \\
Soluble aspirin 300 mg \\
Adrenalin $1: 10002$ mL vial \\
Salbutamol inhaler \\
ald
\end{tabular}

\footnotetext{
${ }^{a}$ For further details and recommended amounts, see New Zealand land search and rescue (NZ LandSAR) website. ${ }^{31}$

$\mathrm{CPR}$, cardiopulmonary resuscitation.
}

analyses, such as problems encountered in specific regions or during a specific activity. The medical and traumatic conditions described in this audit are as transcribed from the NZ Police forms filled in predominantly by nonmedical personnel. It needs to be assumed that neither the medical information regarding preexisting medical conditions nor the final conditions were verified by medical personnel, and the data need to be viewed with these limitations in mind.

\section{Conclusion}

There will be differences in medical and traumatic conditions that SAR teams will encounter both within and between countries, but the similarity in both the demographics of New Zealand wilderness SAR subjects and the epidemiology of their medical and traumatic conditions may allow findings from this audit to be extrapolated to SAR training requirements outside of New Zealand. Although first aid training of SAR personnel needs to concentrate on trauma-related conditions, it must also include teaching skills to cope with many more medical conditions while still being tailored to local need.

Much of the current suggested content of the NZ LandSAR first aid kit seems sensible in light of this audit. Field personnel will continue to need training in the appropriate use of medical kits. To date, no audit has been undertaken of the frequency and appropriateness of the use of NZ LandSAR field first aid kits; that would be a worthwhile area for future study. The findings of this audit were limited by uncertainty about the medical verification of recorded conditions; to finely tune training and equipment needs, it would be desirable to ensure that the medical data entered are verified by qualified medical personnel.

\section{Acknowledgments}

This audit was undertaken as part of a University of Otago Summer Studentship and received financial support from the Royal New Zealand College of General Practitioners and the University of Otago Research Committee. The authors wish to acknowledge the support received from the New Zealand Police in allowing access to their operational knowledge and database, in particular to Senior Sergeant Bruce Johnston, National Coordinator, Search and Rescue. They also wish to thank New Zealand LandSAR staff and volunteers for the input provided.

\section{References}

1. Bauman A, Bull F, Chey T, et al. The International Prevalence Study on Physical Activity: results from 20 countries. Int J Behav Nutr Phys Act. 2009;6:21.

2. SPARC (Sport and Recreation New Zealand). Active New Zealand Survey. Sport and recreation participation profiles levels. Factsheet. Findings from the 2007/08 Active New Zealand Survey. 2009. Available at: http://www.active nzsurvey.org.nz/documents/participation-levels.pdf. Accessed November 7, 2013.

3. Dingwall PR, Fitzharris BB, Owens IF. Natural hazards and visitor safety in New Zealand's national parks. $N$ Z Geographer. 1989;45:68-79.

4. Dignan A, Cessford G. Outdoor recreation participation and incidents in New Zealand. 2009. Available at: http:// www.mountainsafety.org.nz/files/participation-and-incidentgc-fixed.pdf. Accessed November 7, 2009.

5. New Zealand Search and Rescue Council. Annual report 2011-2012. 2012. Available at: http://searchandrescue council.org.nz/portals/0/publications/nzsar\%20annual\% 
20reports/nzsar\%20annual\%20report\%202011-2012.pdf. Accessed November 7, 2013.

6. Urban Search and Rescue (USAR). http://www.fire.org.nz/ about-us/our-organisation/pages/urbansearchandrescue.aspx. Accessed November 21, 2013.

7. New Zealand Land Search and Rescue. LANDSAR yearbook 2011-2012. 2012. Available at: http://www.landsar. org.nz/resource. $\operatorname{aspx}$ ?id=5221. Accessed November 7, 2013.

8. Marsigny B, Lecoq-Jammes F, Cauchy E. Medical mountain rescue in the Mont-Blanc massif. Wilderness Environ Med. 1999;10:152-156.

9. Hearns S. The Scottish mountain rescue casualty study. Emerg Med J. 2003;20:281-284.

10. Johnson RM, Huettl B, Kocsis V, Chan SB, Kordick MF. Injuries sustained at Yellowstone National Park requiring emergency medical system activation. Wilderness Environ Med. 2007;18:186-189.

11. Wild FJ. Epidemiology of mountain search and rescue operations in Banff, Yoho, and Kootenay National Parks, 2003-06. Wilderness Environ Med. 2008;19:245-251.

12. McIntosh SE, Brillhart A, Dow J, Grissom CK. Search and rescue activity on Denali, 1990 to 2008. Wilderness Environ Med. 2010;21:103-108.

13. Lattimore C. Mountaineering emergencies on Denali. J Wilderness Med. 1993;4:358-362.

14. Boore SM, Bock D. Ten years of search and rescue in Yosemite National Park: examining the past for future prevention. Wilderness Environ Med. 2013;24:2-7.

15. Hung EK, Townes DA. Search and rescue in Yosemite National Park: a 10-year review. Wilderness Environ Med. 2007;18:111-116.

16. Heggie TW. Search and rescue in Alaska's national parks. Trav Med Inf Dis. 2008;6:355-361.

17. Ela GK. Epidemiology of wilderness search and rescue in New Hampshire, 1999-2001. Wilderness Environ Med. 2004;15:11-17.

18. Heggie TW, Heggie TM. Search and rescue trends and the emergency medical service workload in Utah's national parks. Wilderness Environ Med. 2008;19:164-171.
19. Heggie TW, Heggie TM. Search and rescue trends associated with recreational travel in US national parks. J Trav Med. 2009;16:23-27.

20. Heggie TW, Amundson ME. Dead men walking: Search and rescue in US national parks. Wilderness Environ Med. 2009;20:244-249.

21. Stephens BD, Diekema DS, Klein EJ. Recreational injuries in Washington State national parks. Wilderness Environ Med. 2005;16:192-197.

22. Malcolm M. Mountaineering fatalities in Mt Cook National Park. N Z Med J. 2001;114:78-80.

23. New Zealand Search and Rescue Council. Annual report 2010-2011. 2011. Available at: http://nzsar.org.nz/portals/ 0/publications/nzsar\%20annual\%20reports/nzsar\%20annual\% 20report\%202010\%202011.pdf. Accessed March;28, 2014.

24. Forrester JD, Holstege CP. Injury and illness encountered in Shenandoah National Park. Wilderness Environ Med. 2009;20:318-326.

25. Gardner TB, Hill DR. Illness and injury among longdistance hikers on the Long Trail, Vermont. Wilderness Environ Med. 2002;13:131-134.

26. Montalvo R, Wingard DL, Bracker M, Davidson TM. Morbidity and mortality in the wilderness. West $\mathrm{J}$ Med. 1998; $168: 248$.

27. Goodman T, Iserson KV, Strich H. Wilderness mortalities: a 13-year experience. Ann Emerg Med. 2001;37:279-283.

28. New Zealand Land Search and Rescue. Medical resources: LandSAR NZ nominated field first aider core competencies and patient care standards. 2009. Available at: http:// www.landsar.org.nz/article.aspx?id=1094. Accessed November 26, 2013.

29. LandSAR Auckland. Available at: http://www.aucklandsar. org.nz/wandatrack/index.html. Accessed April 23, 2013.

30. Koester RJ. Lost Person Behavior: A Search and Rescue Guide on Where to Look-for Land, Air and Water. Charlottesville, VA: dbS Productions; 2008.

31. New Zealand Land Search and Rescue. Medical resources: suggested contents for field team first aid kit. 2009. Available at: http://www.landsar.org.nz/article.aspx?id=1094. Accessed November 26, 2013. 